\title{
Elective Undergraduate Medical Research: A Medical Student Experience
}

Zhi X. Chong.'

\section{The Experience}

About the Author: Zhi Xiong Chong is currently a final-year medical student of a five-year medical programme at school of $\mathrm{Me}$ dical Sciences, Universiti Sains Malaysia, Kelantan, Malaysia. He is the winner of the scientific poster competition at the East Asian Medical Student Conference (EAMSC) in Japan in 2013.
Submission: Mar 6, 2015 Acceptance: Apr 19, 2015 Publication: Jun 8, 2015
Research brings many benefits for undergraduate medical students, and evidence-based medicine (EBM) has been recognized as the most effective paradigm in making clinical decisions.' Regrettably, EBM teaching is often missing from the curriculum at most medical schools in developing countries. Therefore, I would like to share my first research experience to emphasize the importance of research to one's future career.

I was first involved in research while I was in my third year of medical school. At my school, research is optional. I conducted research during that time because I wanted to participate in a scientific poster competition at the East Asian Medical Student Conference (EAMSC) in Japan in 2013. I formed a research team with several of my friends, and that is where our journey began.

For a first-time researcher, the experience can be very challenging and requires a lot of preparation. ${ }^{1,2}$ With little knowledge of how research is conducted, we started to read up on the latest research articles and consulted with several lecturers on where we could start. The theme of the conference was disaster medicine. After several discussions, we decided to conduct a study on the prevalence of post-traumatic stress disorder (PTSD) among flood victims in Malaysia. The decision was based on the consideration that flood is the only disaster which happens annually in Malaysia, especially during the monsoon season.3 Floods can cause both physical injuries and psychological stress to the victims, and more than 10,000 people are affected annually by floods in Malaysia.

The research process lasted three months, from October to December 2012. The first step in the process was proposal writing. We began by learning about proposal writing and how to conduct a literature review on the relevant topics. We learned that proposal writing requires critical thinking and a systematic way of presenting the research concept, and a good proposal will help to plan a good flow for the study. ${ }^{4} \mathrm{~A}$ study has shown that a thorough literature review before proposal writing helps to construct a good study protocol and reduces error during the study. ${ }^{2}$ We managed to complete the proposal after having several discussions with the supervisors. We worked hard to make sure that the proposal format followed the international format strictly.

After we finalised our proposal, we presented the proposal to the Human Research Ethics Committee (HREC) of our university, and the study was approved. The interview with the HREC was a good experience, as we learned the communication skills required to defend our proposal and promote our study. To pass the ethical presentation, we had numerous sleepless nights discussing possible questions which may be asked, and we practised how to best respond to the questions posed by the committee members.

The objective of our study was to compare the prevalence of PTSD among flood victims between Kuala Lumpur, which represented an urban area, and Kelantan, which represented a rural area. Therefore, the data collection was carried out in two different places. We faced several difficulties during the data collection process. Firstly, we did not manage to obtain financial support for our study. As a result, we had to use our own pocket money to prepare the questionnaires and pay for the transportation fees. Secondly, we faced difficulties during the recruitment of study participants. The subjects were recruited on a voluntary basis, and some of the flood victims we approached asked to be paid to participate in the study. As a result, we faced some problems in recruiting enough participants during the initial stage. As time passed, with effort and determination, we managed to obtain a sample with adequate sample size and completed the data collection.

The next challenge was the data analysis. Statistical Package for the Social Sciences (SPSS) is the commonest statistical analytical tool for data interpretation in the medical field. ${ }^{2}$ SPSS allows for a systematic and objective means of analysing the data collected. ${ }^{4}$ However, a study has shown that most medical students are not familiar with SPSS, and the reasons could be the lack of interest and the lack of tutorials. ${ }^{5}$ Most of us were inexperienced in performing statistical analysis, so we had to search online for SPSS tutorials and articles to learn how to analyse data using SPSS. With the help of the statistician at our school, we successfully completed the analysis and managed to proceed to the discussion of the study.

${ }^{1}$ Universiti Sains Malaysia, Malaysia. 


\section{Experience}

Chong ZX.

The discussion came easily to us because it mainly involved using our literature review and comparing our study results with those of previous studies. In the end, it took us three months to complete our research. Our project was represented at the national level selection competition and won the only place allocated to Malaysia to represent the country at the final competition in EAMSC in Japan.

In January 2013, the study was presented during the scientific poster competition at EAMSC Japan and was announced as the winning poster. However, that did not mark the end of our journey. After the conference, we wrote a research manuscript and submitted it to an international journal for publication. The manuscript was accepted and is expected to be published in 2015.

Medical students are future doctors. With the advances in science and technology in the field of medicine, EBM and research are becoming more important in disease management. Including scientific research training into medical school curriculum can train junior doctors to make clinical decisions which are based on the latest evidence. This reduces medico-legal errors and improves diagnostic accuracy. ${ }^{5}$ Additionally, exposing students to research early in their undergraduate study can nurture their interest in research and motivate them to become tomorrow's scientists. At the same time, undergraduate medical research improves the curriculum vitae of a student, but this should not be the primary aim for a medical student to get involved in medical research.

To encourage more medical schools to introduce research into their undergraduate medical curriculum, several strategies can be considered. Firstly, introducing research elective programmes whereby pre-clinical students will do research in a group during a semester break as part of the elective programme may prove advantageous. Secondly, encouraging medical students to participate in scientific research competitions at the national or international level indirectly encourages them to do research. Students who have done research before can share their experiences with their friends and juniors to improve their understandings on research. More funds should be allocated to medical schools, so that they could employ experienced lecturers to teach the students on research. On top of that, financial support is also needed to help students gain access to the latest articles and guidelines. This allows them to have the opportunities to read the latest evidence and further increase their interest in research.

In conclusion, my first research gave me a very memorable experience. From the original idea to participation in an international medical student conference and the publication of the research report in an international journal, the journey was not easy but nonetheless enjoyable. I learned how to conduct research and met new friends. My communication, leadership, and writing skills were improved after the research experience. Even though the process was tough, I would still recommend all medical students worldwide to try to conduct research at some stage of their student life to broaden their view of life and gain new experiences.

\section{References}

1. Al-Husseini M. Research as a student: is it worth a try? An insightful experience from a Middle Eastern student. Int J Med Students. 2014 MarJun;2(2):71-3.

2. Burgoyne LN, O'Flynn S, Boylan GB. Undergraduate medical research: the student perspective. Med Educ Online. 2010 Sep 10;15.

3. Baharuddin KA, Abdul Wahab SF, Nik Ab Rahman NH, Nik Mohamad NA, Tuan Kamaruzaman TH, Md Nor AY, et al. The record-setting flood of 2014 in Kelantan: challenges and recommendations from an emergency medicine perspective and why the medical campus stood dry. Malays J Med Sci. 2015 Mar-Apr;22(2):1-7.

4. Boyle KM. How to prepare a dissertation proposal: suggestions for students in education at the social and behavioral sciences (review). J Coll Stud Dev. 2007 Mar-Apr;48(2):232-4.

5. Madan CR, Teitge BD. The benefits of undergraduate research: the student's perspective. The Mentor: An Academic Advising Journal. 2013 May 1:1-3.

6. Chong ZX, Ho JH, Chang WL, Chong WL, Khong SC, Ing SK, et al. Prevalence of post-traumatic stress disorder (PTSD) among flood victims in Malaysia: difference between Kuala Lumpur and Kelantan. Int Med J. Forthcoming 2015.

\section{Acknowledgments}

The author would like to express gratitude to supervisors, co-researchers, research participants and everyone who has directly or indirectly helped the researchers throughout the study period.

Conflict of Interest Statement at Funding

The author has no funding, financial relationships or conflicts of interest to disclose.

Author Contributions

Conception and design the work/idea, Write the manuscript, Critical revision of the manuscript, Approval of the final version: ZXC.

Cite as:

Chong ZX. Elective Undergraduate Medical Research: A Medical Student Experience. Int J Med Students. 2015 Apr-Aug;3(2)>115-6. 